\title{
ANALISIS KUALITAS PELAYANAN PUBLIK TERHADAP KEPUASAN KONSUMEN DENGAN MENGGUNAKAN METODE SERVPERF-IPA-CSI
}

\author{
Annisa Azzahra Handriati ${ }^{1)}$ Sunaryo $^{2)}$ Vembri Noor Helia ${ }^{3)}$ \\ Jurusan Teknik Industri, Fakultas Teknologi Industri, Universitas Islam Indonesia ${ }^{1,2)}$ \\ Jl. Kaliurang km. 14 Sleman Yogyakarta \\ Telepon (0274) 895287 ekst 147 \\ E-mail : azzahrannisa@yahoo.com ${ }^{l)}$
}

\begin{abstract}
Customer satisfaction is the most important aspect in order to improve services of Jombor bus station in Sleman-Yogyakarta. The research aims to find out service performance provided in the Jombor bus station, and to give an overview of vicinity condition which can be used to improve services quality for the customer. Methods used in this research are: Service performance (Servperf), Importance Performance Analysis (IPA), and Customer Satisfaction Index (CSI). Servperf method with five measuring attribute such as tangibles, responsiveness, assurance, empathy, reability is used to determine the rate of service performance. Furthermore, there are 17 questions provided in order to collect the data. Based on Importance Performance Analysis, there are four service attributes having high level of interest, and low service performance. They are: fineness, cleanliness, and mildness of passenger waiting room, and praying room, also the bus condition, and the safety of bus station zone. The result shows that consumers feel less satisfied with services provided by Jombor bus station management. It because based on the calculation of customer satisfaction index, value $71 \%$ is classified as poor condition. Several advices have been given in order to improve the consumer satisfaction such as, inspection of bus condition, renovation of passenger waiting room, rest room, and praying room including the availability of electric equipment such as: speaker, microphone, CCTV, and announcement board. Moreover, in order to reduce the air pollution, the Jombor bus station is suggested to grow some plants in its environment.
\end{abstract}

Keywords: Service Performance, Importance Performance Analysis, Customer Satisfaction Index.

\section{PENDAHULUAN}

Yogyakarta merupakan salah satu daerah pariwisata yang sering dikunjungi oleh wisatawan baik dalam dan luar negri. Banyaknya alat transportasi yang dapat digunakan melalui jalur darat, laut dan udara untuk berpergian ke Yogyakarta. Salah satunya adalah melalui jalur darat dengan menggunakan bus. Transportasi digunakan untung menggerakan dan memindahkan orang atau barang, sehingga nilai dari orang atau barang yang diangkut akan menjadi lebih tinggi di tempat tujuan dibandingkan di tempat asal.
Meningkatnya arus pergerakan dari tahun ke tahun merupakan dampak yang timbul dari kota pariwisata sehingga memerlukan bus sebagai salah satu sarana transportasi untuk melakukan pergerakan, selain itu perlu adanya prasarana terminal yang memadai. Terminal bus merupakan suatu area dan fasilitas yang di dalamnya terdapat interaksi berbagai elemen seperti manusia (penumpang, pedagang dan kru bus).

Terminal merupakan salah satu fasilitas publik di bawah naungan Dinas Perhubungan \& Kementrian Informasi, pemerintah perlu meningkatkan kualitas pelayanan bagi 
penumpang bus. Peningkatan kualitas suatu pelayanan jasa perlu dilakukan untuk memenuhi kebutuhan dan kepuasan penumpang bus.

Pengukuran terhadap kualitas pelayanan perlu dilakukan untuk mendapatkan peningkatan kualitas pelayanan dan evaluasi sehingga instansi tersebut memiliki pelanggan yang setia. Apabila pemberian kualitas pelayanan yang buruk dapat membuat pelanggan semakin kecewa dan citra instansi tersebut berkurang di mata pelanggan.

Terdapat beberapa metode untuk melakukan pengukuran kualitas jasa. Salah satu metode yang sering digunakan untuk mengukur kualitas pelayanan jasa adalah service performance. Kualitas jasa berbasis kinerja (service performance) merupakan basis pengukuran kualitas jasa yang paling baik. Masalah yang ada pada servqual diatasi oleh servperf dengan menginvestigasi hubungan antara kualitas jasa, kepuasan pelanggan dan purchase intentions. Penilaian kualitas jasa pelayanan dimaksudkan untuk menentukan atribut dan tingkat kepuasaan konsumen terhadap kualitas atribut jasa pelayanan tersebut. Pengembangan metode servperf memiliki keunggulan tersendiri di mana pengukurannya didasarkan pada kinerja proses layanan.

Berbeda dengan servqual, servperf memiliki keunggulan dapat memberikan informasi atribut kualitas pelayanan manakah yang penting untuk diperbaiki, sehingga antara keinginan dan kepentingan dapat menjadi lebih tampak dalam analisa atribut kualitas layanan. Tingkat kepuasan pelanggan secara keseluruhan dapat diukur menggunakan customer satisfaction index.

Beberapa pelayanan terminal di jombor belum memenuhi kepuasaan pelanggan, seperti dapat dilihat sirkulasi kendaraan yang kurang teratur, di mana kendaraan pengantar/pengunjung yang parkir tidak tertata dengan rapih dan parkir disembarang tempat, terdapat beberapa fasilitas yang kurang lengkap dan belum dikelola dengan semaksimal mungkin. Oleh karena itu perlu dilakukan sebuah penelitian yang bertujuan untuk memberikan gambaran kondisi terminal bus yang ada sehingga dapat melakukan pengembangan dan meningkatkan kualitas pelayanan terminal. Berdasarkan data tersebut selanjutnya dapat diberikan usulan perbaikan terhadap fasilitas dan lingkungan terminal.

Penelitian ini dilakukan di Terminal Bus Jombor Sleman sebagai obyek penelitian, Penelitian sebelumnya telah dilakukan oleh beberapa peneliti, namun dengan nama tempat, obyek dan beberapa metode berbeda yang digunakan. Berikut ini adalah beberapa penelitian terdahulu, guna memperkuat penelitian yang sedang dilakukan, yaitu: Setyaningsih (2013) dengan judul "Analisis Kualitas Pelayanan Rumah Sakit Terhadap Pasien Menggunakan Pendekatan Lean Servperf (Lean Service dan Service Performance) (Studi Kasus Rumah Sakit X)", Siregar (2006) dengan judu "Analisis Tingkat Kualitas Pelayanan dengan Metode Index Potential Gain Customer Value (PGCV) di PT Bank Muamalat Indonesia Medan" dan Hudaya (2011) dengan judul "Peningkatan Kualitas Pelayanan di Unit Farmasi Rawat Jalan Berdasarkan Tingkat Kepuasan Pelanggan Menggunakan Pendekatan Lean Servperf (Studi Kasus di Rumah Sakit PKU Muhammadiyah)". Sukania (2013) dengan judul "Kajian Ergonomi di Terminal Bus Jakarta”.

\section{LANDASAN TEORI}

\section{1 Definisi Jasa}

Jasa adalah setiap kegiatan atau manfaat yang ditawarkan kepada pihak lain yang pada dasarnya tidak berwujud dan tidak menghasilkan kepemilikan sesuatu. Proses produksinya mungkin juga tidak dikaitkan dengan suatu produk fisik.

\section{2 Definisi Terminal}

Terminal Penumpang adalah prasarana transportasi darat untuk keperluan menaikkan dan menurunkan penumpang, perpindahan 
intra dan/atau antar moda transportasi serta pengaturan kedatangan dan pemberangkatan kendaraan umum.

\section{3 Kualitas Pelayanan Jasa}

Pelayanan adalah setiap tindakan atau kegiatan yang dapat ditawarkan oleh suatu pihak kepada pihak lain yang pada dasarnya tidak berwujud dan tidak mengakibatkan kepemilikan apapun. Produksinya dapat dikaitkan atau tidak dikaitkan pada satu produk fisik. Pelayanan merupakan perilaku produsen dalam rangka memenuhi kebutuhan dan keinginan konsumen demi tercapainya kepuasan pada konsumen itu sendiri.

Berdasarkan definisi tentang kualitas pelayanan tersebut dapat diambil kesimpulan bahwa kualitas pelayanan adalah segala bentuk aktivitas yang dilakukan oleh perusahaan guna memenuhi harapan konsumen. Pelayanan dalam hal ini diartikan sebagai jasa atau service yang disampaikan oleh pemilik jasa yang berupa kemudahan, kecepatan, hubungan, kemampuan dan keramah-tamahan yang ditujukan melalui sikap dan sifat dalam memberikan pelayanan untuk kepuasan konsumen. Faktor-faktor yang mempengaruhi kualitas pelayanan adalah:

1. Keandalan (Reliability)

Suatu kemampuan dalam memenuhi janji (tepat waktu, konsisten, kecepatan dalam pelayanan) merupakan suatu hal yang penting dalam pelayanan.

2. Bukti langsung (Tangibles)

Penampilan dan kemampuan sarana dan prasarana fisik harus dapat diandalkan, keadaan lingkungan sekitarnya adalah bukti nyata dari pelayanan yang diberikan oleh pemberi jasa. Penampilan fisik pelayanan (seperti penampilan fisik, perlatan),

3. Daya tanggap (Responsiveness)

Suatu kebijakan untuk membantu dan memberikan pelayanan yang cepat (responsif) kepada pelanggan, membiarkan konsumen menunggu tanpa adanya suatu alasan yang menyebabkan persepsi yang negatif dalam kualitas pelayanan.

4. Jaminan (Assurance)

Pengetahuan dan keramahan petugas serta kemampuan melaksanakan tugas secara spontan yang dapat menjamin kinerja yang baik sehingga menimbulkan kepercayaan dan keyakinan pelanggan.

5. Empati (Empathy)

Memberikan perhatian yang bersifat individual atau pribadi kepada pelanggan dan berupaya untuk memahami keinginan konsumen.

\section{4 Kepuasan Konsumen}

Kepuasan pelanggan adalah hasil (outcome) yang dirasakan atas pengguna produk atau jasa, sama atau melebihi harapan yang diinginkan. Terdapat beberapa faktor yang mempengaruhi kepuasan konsumen antara lain: biaya, harga, emosi, kualitas pelayanan dan kualitas produk.

\section{5 Service Performance}

Service performance adalah kinerja dari pelayanan yang diterima oleh konsumen itu sendiri dan menilai kualitas dari pelayanan yang benar-benar mereka rasakan.

\section{METODOLOGI PENELITIAN}

\section{1 Tempat dan Objek Penelitian}

Penelitian ini dilakukan di Terminal Bus Jombor Sleman bertempat di Jalan Magelang. Objek penelitian ini adalah penumpang bus yang pernah merasakan pelayanan di terminal bus Jombor Sleman. Penentuan ukuran sampel berdasarkan analisis faktor adalah ukuran sampel 100 responden atau lebih. Beberapa peneliti merekomendasikan rasio 10:1 atau 20:1 kasus untuk setiap atribut. Ukuran sampel dalam penelitian ini berjumlah 180 penumpang bus.

\section{2 Metode Pengumpulan Data}

Metode atau teknik pengumpulan data adalah cara yang dilakukan seorang peneliti untuk mendapatkan data yang diperlukan. 
Metode pengumpulan data pada penelitian ini adalah:

1. Studi lapangan

a. Observasi

Penelitian dilakukan dengan cara pengamatan langsung keadaan dan kegiatan terhadap penumpang dan penyedia jasa terminal bus Jombor.

b. Kuisioner

Kuisioner dalam penelitian ini berupa daftar pertanyaan tertulis yang diberkan langsung kepada responden untuk mendapatkan informasi mengenai penilaian atribut pelayanan jasa yang diberikan oleh terminal bus jombor berdasarkan beberapa dimensi kualitas pelayanan yaitu tangibles, responsiveness, empathy, reability dan assurance.

c. Wawancara

Teknik wawancara dalam penelitian ini adalah melakukan tanya jawab dengan petugas di terminal jombor, petugas Dinas Perhubungan, Komunikasi dan Informatika (Dishub \& Kominfo) dan beberapa agen yang ada di terminal Jombor.

\section{Studi Literatur}

Studi literatur diperoleh dari data perusahaan, serta mengadakan studi penelaahan terhadap buku-buku, literatur-literatur yang berhubungan dengan penelitian yang sedang dilakukan.

\section{3 Uji Validitas}

Uji validitas dilakukan dengan tujuan sebagai petunjuk sejauh mana suatu alat pengukur (instrumen) mengukur apa yang ingin diukur.

$r=\frac{N\left(\sum X_{i} Y_{i}\right)-\left(\sum X_{i} \cdot \sum Y_{i}\right)}{\sqrt{\left[N \sum X_{1}^{2}-\left(\sum X_{1}\right) 2\right] \cdot\left[N \cdot \sum Y_{1}^{2} \cdot\left(\sum Y_{i}\right) 2\right]}} \ldots$

Diketahui:

$\mathrm{N} \quad=$ Jumlah subjek (responden)

$\Sigma \mathrm{X}=$ Jumlah $\mathrm{x}$ (skor butir)

$\Sigma X^{2}=$ Jumlah skor butir kuadrat
$\Sigma \mathrm{Y}=$ Jumlah y (skor faktor)

$\Sigma Y^{2}=$ Jumlah skor faktor kuadrat

$\Sigma \mathrm{XY}=$ Jumlah perkalian $\mathrm{x} \& \mathrm{y}$

1. Menentukan Hipotesis

$\mathrm{H}_{\mathrm{o}}=$ Dikatakan pertanyaan kuisioner valid

$\mathrm{H}_{1}=$ Dikatakan pertanyaan kuisioner tidak alid

2 Menentukan Nilai $r_{\text {tabel }}$

Tingkat signifikansi $5 \%$ derajat kebebasan $(\mathrm{df})=\mathrm{n}-2$, maka nilai $\mathrm{r}_{\text {tabel }}$ dapat dilihat pada tabel $r$.

3. Mencari Nilai $r_{\text {hitung }}$

Nilai $r_{\text {hitung didapatkan melalui }}$ perhitungan menggunakan software SPSS 22 for windows dapat dilihat pada nilai Correct Item - Total Corelation.

4. Membuat Keputusan

Apabila nilai $r_{\text {hitung }}$ bernilai positif, serta $r_{\text {hitung }} \geq r_{\text {tabel }}$, maka atribut tersebut valid. Apabila nilai $r_{\text {hitung }}$ bernilai positif, serta $\mathrm{r}_{\text {hitung }} \leq \mathrm{r}_{\text {tabel }}$, maka atribut tersebut tidak valid.

Apabila nilai $r_{\text {hitung }}$ bernilai negatif, serta $\mathrm{r}_{\text {hitung }} \leq \mathrm{r}_{\text {tabel }}$, maka atribut tersebut tidak valid.

\section{4 Uji Reliabilitas}

Uji reliabilitas ini adalah untuk mengetahui apakah hasil pengukuran tersebut dapat dipercaya untuk digunakan dalam pengumpulan data atau tidak.

$$
\mathrm{ri}=\frac{k}{k-1}\left[1-\frac{\sum \sigma b^{2}}{\sigma t^{2}}\right]
$$

Diketahui:

ri $=$ Reliabilitas Instrumen

$\mathrm{k}=$ Banyaknya Butir Pernyataan

$\sum \sigma b^{2}=$ Jumlah Varians Butir

$\sigma t^{2}=$ Varians Total

1. Menentukan Hipotesis

$\mathrm{H}_{\mathrm{o}}=$ Dikatakan kuisioner pertanyaan reliable

$\mathrm{H}_{1}=$ Dikatakan kuisioner pertanyaan tidak reliable 
2. Menentukan Nilai $\mathbf{r}_{\text {tabel }}$

Tingkat signifikansi $5 \%$ derajat kebebasan $(\mathrm{df})=\mathrm{n}-2$, maka nilai $\mathrm{r}_{\text {tabel }}$ dapat dilihat pada tabel $r$.

3. Mencari Nilai $r_{\text {hitung }}$

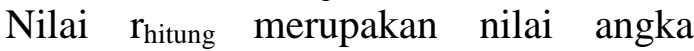
Cronbach's Alpha yang bisa dilihat pada pengolahan dengan menggunakan software SPSS 22 for windows.

4. Mambuat Keputusan

Apabila nilai $r_{\text {hitung }}$ bernilai positif, serta $\mathrm{r}_{\text {hitung }} \geq 0,6$, maka atribut tersebut reable.

Apabila nilai $r_{\text {hitung }}$ bernilai positif, serta

$\mathrm{r}_{\text {hitung }} \leq 0,6$, maka atribut tersebut tidak reable.

Apabila nilai $r_{\text {hitung }}$ bernilai negatif, serta $\mathrm{r}_{\text {hitung }} \leq 0,6$, maka atribut tersebut tidak reable

\section{5 Pengukuran Service Performance}

Penilaian penumpang bus terhadap tingkat kepentingan dan tingkat kepuasan diolah menggunakan metode servperf untuk mendapatkan rata-rata tingkat kepentingan dan kepuasan. Angka kepuasan/kinerja penumpang bus diolah dengan rumus:

$S Q_{i}=\frac{1}{m} \sum_{j=1} k P S_{i j}$

Diketahui :

$\mathrm{SQ}_{\mathrm{i}}=$ Angka tingkat kepuasan untuk atribut $\mathrm{i}$

$\mathrm{PS}_{\mathrm{ij}}=$ Total nilai jawaban responden tingkat kepuasan untuk atribut $\mathrm{i}$

$\mathrm{m}=$ Total responden

$\mathrm{k}=$ Jumlah atribut pertanyan

Angka kepentingan diolah dengan rumus:

$S Q_{i}=\frac{1}{m} \sum_{j=1} k I S_{i j}$

Diketahui :

$\mathrm{SQ}_{\mathrm{i}}=$ Angka tingkat kepentingan untuk atribut $\mathrm{i}$

$\mathrm{IS}_{\mathrm{ij}}=$ Total nilai jawaban responden tingkat kepentingan untuk atribut $i$

$\mathrm{m}=$ Total responden

$\mathrm{k}=$ Jumlah atribut pertanyan

\section{6 Importance Performance Analysis}

Matriks IPA awalnya hanya memiliki 2 dimensi, $\mathrm{x}$ dan y saja. Sumbu x menunjukkan performance (kepuasan konsumen), sedangkan y menunjukkan tingkat kepentingan.

Matriks ini sangat bermanfaat sebagai pedoman dalam mengalokasikan sumber daya organisasi yang terbatas pada bidangbidang spesifik, di mana perbaikan kinerja bisa berdampak besar pada kepuasan pelanggan total. Selain itu, matriks ini juga menunjukkan bidang atau atribut tertentu yang perlu dipertahankan dan aspek-aspek yang perlu dikurangi prioritasnya.

1. Analisis Tingkat Kesesuaian

Analisis tingkat kesesuaian yang berfungsi untuk menentukan urutan prioritas peningkatan kualitas layanan yang paling baik agar memperbaiki kepuasan penumpang bus.

$$
T K=\frac{\overline{\boldsymbol{x}}_{i}}{\overline{\boldsymbol{y}}_{i}} \times 100 \%
$$

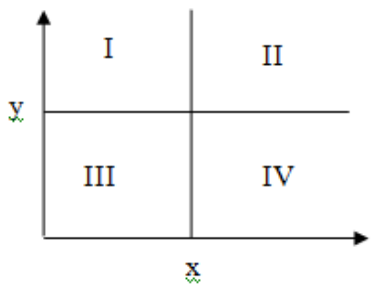

Gambar 1. Kuadran Importance Performance Analysis

Strategi yang dapat dilakukan berkenaan dengan posisi masing-masing variabel pada keempat kuardan tersebut dapat dijelaskan sebagai berikut :

a. Kuadran 1 (Concentrate These)

Wilayah yang memuat faktor-faktor yang dianggap penting oleh pelanggan, tetapi pada kenyataannya faktor-faktor ini belum sesuai dengan harapan pelanggan (tingkat kepuasan yang diperoleh masih rendah). Variabel-variabel yang masuk dalam kuadran ini harus ditingkatkan. 
b. Kuadran 2 (Keep Up The Good Work) Wilayah yang memuat faktor-faktor yang dianggap penting oleh pelanggan dan faktor-faktor yang dianggap pelanggan sudah sesuai dengan yang dirasakannya sehingga tingkat kepuasannya relatif lebih tinggi. Variabel-variabel yang masuk dalam kuadran ini harus tetap dipertahankan karena semua variabel ini menjadikan produk atau jasa unggul di mata pelanggan.

c. Kuadran 3 (Low Priority)

Wilayah yang memuat faktor-faktor yang dianggap kurang penting oleh pelanggan, dan pada kenyatannya kinerjanya tidak terlalu istimewa. Peningkatan variabel-variabel yang termasuk dalam kuadran ini dapat dipertimbangkan kembali karena pengaruhnya terhadap manfaat yang dirasakan oleh pelanggan sangat kecil.

d. Kuadran 4 (Possible Overkill)

Wilayah yang memuat faktor-faktor yang dianggap kurang penting oleh pelanggan dan dirasakan terlalu berlebihan. Variabel-variabel yang termasuk dalam kuadran ini dapat dikurangi agar perusahaan dapat menghemat biaya.

\section{7 Customer Satisfaction Index}

Customer Satisfaction Index (CSI) digunakan untuk mengetahui tingkat kepuasan pengunjung secara menyeluruh dengan melihat tingkat kepentingan dari atribut-atribut produk/jasa. Besarnya CSI dapat diketahui dengan langkah-langkah sebagai berikut:

a. Menentukan Mean Importance Score (MIS) tiap-tiap atribut, nilai ini berasal dari rata-rata kepentingan tiap konsumen dengan rumus:

$M I S=\frac{\sum_{i=1}^{n} Y_{i}}{n}$
Diketahui:

$\mathrm{n}=$ Jumlah pengunjung

$Y_{\mathrm{i}}=$ Nilai kepentingan atribut $\mathrm{Y}$ ke-i

b. Membuat Weight Factors (WF) per atribut. Bobot ini merupakan prosentase nilai $M I S$ per atribut terhadap total $M I S$ seluruh atribut dengan rumus:

$$
W F=\frac{M I S_{i}}{\sum_{i=1}^{p} M I S_{i}} \times 100 \%
$$

Diketahui:

$\mathrm{I}=$ Atribut kepentingan ke-i

c. Menentukan Mean Satisfaction Score (MSS) tiap atribut.

$$
M S S=\frac{\sum_{i=1}^{n} X_{i}}{n}
$$

d. Membuat Weight Score (WSk) tiap atribut. Bobot ini merupakan perkalian antara WFk dengan MSSk dengan rumus:

$$
\mathrm{WS}_{\mathrm{i}}=\mathrm{WF}_{\mathrm{i}} \mathrm{MSS}
$$

e. Menghitung Customer Satisfaction Index, yaitu Weight Total (WT) dibagi skala maksimum yang digunakan, kemudian dikalikan 100\%. Tingkat kepuasan responden secara keseluruhan dapat dilihat dari kriteria tingkat kepuasan.

$$
C S I=\frac{\sum_{i=1}^{P} W S_{i}}{H S} \times 100 \%
$$

Diketahui:

$$
\begin{aligned}
& \text { CSI = Customer satisfaction Index }(\%) \\
& \mathrm{WS}_{\mathrm{i}}=\text { Weight } \text { Score } \\
& \mathrm{i}=\text { Atribut kepentingan ke- } \mathrm{i} \\
& \mathrm{HS}=\text { Skala maksimum yang digunakan }
\end{aligned}
$$

Nilai CSI dalam penelitian ini dibagi ke dalam tujuh kriteris dari sangat tidak baik sampai baik sekali. Berikut ini adalah tabel CSI: 
Tabel 1. Kriteria Customer Satisfaction Index

\begin{tabular}{ccc}
\hline No & Nilai Index $(\%)$ & Kriretia CSI \\
\hline 1 & $\mathrm{X} \leq 64 \%$ & Very Poor \\
2 & $64 \%<\mathrm{X} \leq 71 \%$ & Poor \\
3 & $71 \%<\mathrm{X} \leq 77 \%$ & Cause for Concern \\
4 & $77 \%<\mathrm{X} \leq 80 \%$ & Borderline \\
5 & $80 \%<\mathrm{X} \leq 84 \%$ & Good \\
6 & $84 \%<\mathrm{X} \leq 87 \%$ & Very Good \\
7 & $87 \%<$ & Excelent \\
\hline
\end{tabular}

Ket : X : Angkat Kepuasan Penumpang ;

Sumber :Customer Satisfaction Measurement,

Satisfaction Indexwww. leadershipfactor. com

\section{HASIL PENELITIAN DAN PEMBAHASAN}

\subsection{Hasil Penelitian}

\subsubsection{Uji Validitas}

Tabel 2. Uji Validitas

\begin{tabular}{clccc}
\hline No & \multicolumn{1}{c}{ Atribut } & $\mathbf{r}_{\text {hitung }}$ & $\mathbf{r}_{\text {tabel }}$ & Keputusan \\
\hline 1 & Ruang tunggu yang nyaman & 0.613 & 0.1463 & Valid \\
2 & Penampilan karyawan yang rapih dan enak dipandang & 0.556 & 0.1463 & Valid \\
3 & Loket agen yang cukup memadai & 0.663 & 0.1463 & Valid \\
4 & Musholla \& Toilet yang nyaman dan terdapat alat sholat & 0.568 & 0.1463 & Valid \\
5 & Kondisi bus yang baik & 0.617 & 0.1463 & Valid \\
6 & Pintu masuk dan keluar yang mudah dijangkau & 0.628 & 0.1463 & Valid \\
7 & Tempat parkir dan pengelolaan yang aman dan strategis & 0.601 & 0.1463 & Valid \\
8 & Kemudahan proses pembelian tiket & 0.785 & 0.1463 & Valid \\
9 & Kejelasan jadwal keberangkatan dan kedatangan bus & 0.817 & 0.1463 & Valid \\
10 & Kecepatan dan ketepatan proses pelayanan & 0.806 & 0.1463 & Valid \\
11 & Pelayanan yang adil kepada semua pihak & 0.768 & 0.1463 & Valid \\
12 & Karyawan cepat tanggap terhadap masalah atau keluhan & 0.728 & 0.1463 & Valid \\
& penumpang & & & Valid \\
13 & Karyawan yang ikhlas dan tepat dalam memberikan & 0.842 & 0.1463 & \\
& keterangan dan informasi & & & Valid \\
14 & Pengangkutan dan penurunan penumpang sesuai dengan & 0.674 & 0.1463 & Valid \\
lokasi yang dituju & Keamanan di lokasi terminal bus & 0.785 & 0.1463 & Valid \\
\hline & Karyawan bersikap dan berkomunikasi dengan ramah & 0.79 & 0.1463 & \\
& dan sopan & & & \\
\hline
\end{tabular}

\subsubsection{Uji Reliabilitas}

Table 3. Uji Reliabilitas

\begin{tabular}{ccccc}
\hline No & & $\mathbf{r}_{\text {hitung }}$ & $\mathbf{r}_{\text {tabel }}$ & Keputusan \\
\hline 1 & Tingkat Kepentingan & 0.945 & 0.1463 & Reliable \\
2 & Tingkat Kinerja & 0.864 & 0.1463 & Reliable \\
\hline
\end{tabular}




\subsubsection{Perhitungan Service Performance}

Tabel 4. Perhitungan Servperf dan IPA

\begin{tabular}{|c|c|c|c|c|c|}
\hline No & Atribut & $\begin{array}{c}\text { Tingkat Kinerja } \\
\text { (X) }\end{array}$ & $\begin{array}{c}\text { Tingkat } \\
\text { Kepentingan } \\
\text { (Y) }\end{array}$ & $\bar{x}$ & $\overline{\boldsymbol{y}}$ \\
\hline 1 & T1 & 448 & 633 & 2.49 & 3.52 \\
\hline 2 & $\mathrm{~T} 2$ & 501 & 597 & 2.78 & 3.32 \\
\hline 3 & $\mathrm{~T} 3$ & 526 & 618 & 2.92 & 3.43 \\
\hline 4 & $\mathrm{~T} 4$ & 431 & 638 & 2.39 & 3.54 \\
\hline 5 & T5 & 473 & 645 & 2.63 & 3.58 \\
\hline 6 & T6 & 548 & 626 & 3.04 & 3.48 \\
\hline 7 & $\mathrm{~T} 7$ & 462 & 617 & 2.57 & 3.43 \\
\hline 8 & $\mathrm{R} 1$ & 570 & 648 & 3.17 & 3.60 \\
\hline 9 & $\mathrm{R} 2$ & 524 & 642 & 2.91 & 3.57 \\
\hline 10 & R3 & 532 & 631 & 2.96 & 3.51 \\
\hline 11 & R4 & 552 & 645 & 3.07 & 3.58 \\
\hline 12 & RS1 & 530 & 633 & 2.94 & 3.52 \\
\hline 13 & A1 & 548 & 647 & 3.04 & 3.59 \\
\hline 14 & A2 & 546 & 630 & 3.03 & 3.50 \\
\hline 15 & A3 & 478 & 647 & 2.66 & 3.59 \\
\hline 16 & E1 & 538 & 642 & 2.99 & 3.57 \\
\hline
\end{tabular}

Total

45.59

56.33

Rata-Rata

2.85

3.52

Tabel 5. Keputusan H\&A

\begin{tabular}{cccc}
\hline No & Atribut & $\begin{array}{c}\text { Tingkat } \\
\text { Kesesuaian }\end{array}$ & $\begin{array}{c}\text { Keputusan } \\
\text { H\&A }\end{array}$ \\
\hline 1 & $\mathrm{~T} 1$ & $71 \%$ & $\mathrm{~A}$ \\
2 & $\mathrm{~T} 2$ & $84 \%$ & $\mathrm{H}$ \\
3 & $\mathrm{~T} 3$ & $85 \%$ & $\mathrm{H}$ \\
4 & $\mathrm{~T} 4$ & $68 \%$ & $\mathrm{~A}$ \\
5 & $\mathrm{~T} 5$ & $73 \%$ & $\mathrm{~A}$ \\
6 & $\mathrm{~T} 6$ & $88 \%$ & $\mathrm{H}$ \\
7 & $\mathrm{~T} 7$ & $75 \%$ & $\mathrm{~A}$ \\
8 & $\mathrm{R} 1$ & $88 \%$ & $\mathrm{H}$ \\
9 & $\mathrm{R} 2$ & $82 \%$ & $\mathrm{H}$ \\
10 & $\mathrm{R} 3$ & $84 \%$ & $\mathrm{H}$ \\
11 & $\mathrm{R} 4$ & $86 \%$ & $\mathrm{H}$ \\
12 & $\mathrm{RS} 1$ & $84 \%$ & $\mathrm{H}$ \\
13 & $\mathrm{~A} 1$ & $85 \%$ & $\mathrm{H}$ \\
14 & $\mathrm{~A} 2$ & $87 \%$ & $\mathrm{H}$ \\
15 & $\mathrm{~A} 3$ & $74 \%$ & $\mathrm{~A}$ \\
16 & $\mathrm{E} 1$ & $84 \%$ & $\mathrm{H}$ \\
\hline \multicolumn{3}{c}{ Total } \\
\hline \multicolumn{3}{c}{$1295 \%$} \\
\hline \multicolumn{3}{c}{$81 \%$} \\
\hline
\end{tabular}




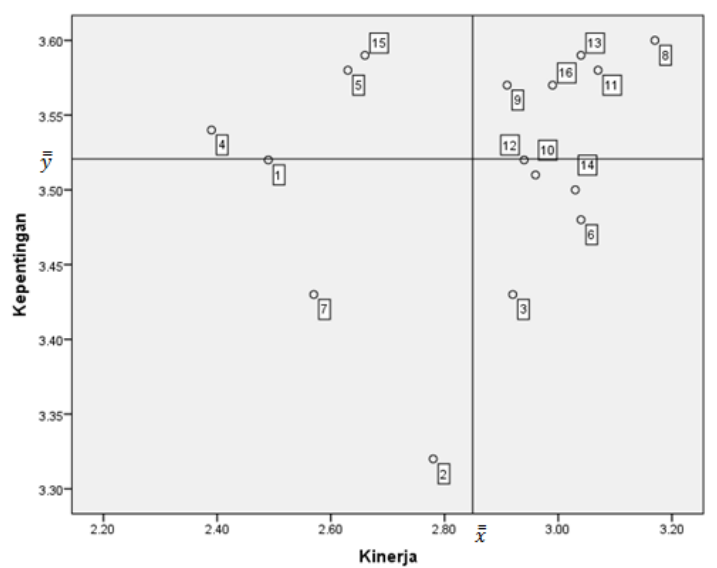

Gambar 2. Diagram Kartesius

\subsubsection{Perhitungan Customer Satisfaction Index}

Tabel 6. Perhitungan Customer Satisfaction Index

\begin{tabular}{|c|c|c|c|c|c|c|c|}
\hline \multirow[b]{2}{*}{ No } & \multicolumn{2}{|c|}{ Kepentingan (Y) } & \multicolumn{2}{|c|}{ Kinerja (X) } & \multirow[b]{2}{*}{ WF\% } & \multirow[b]{2}{*}{ WS } & \multirow[b]{2}{*}{ CSI } \\
\hline & $\sum \mathbf{Y}$ & $\begin{array}{l}\text { Nilai } \\
\text { MIS }\end{array}$ & $\sum \mathbf{X}$ & $\begin{array}{l}\text { Nilai } \\
\text { MSS }\end{array}$ & & & \\
\hline 1 & 633 & 3.52 & 448 & 2.49 & $6 \%$ & 0.16 & \multirow{16}{*}{$71 \%$} \\
\hline 2 & 597 & 3.32 & 501 & 2.78 & $6 \%$ & 0.16 & \\
\hline 3 & 618 & 3.43 & 526 & 2.92 & $6 \%$ & 0.18 & \\
\hline 4 & 638 & 3.54 & 431 & 2.39 & $6 \%$ & 0.15 & \\
\hline 5 & 645 & 3.58 & 473 & 2.63 & $6 \%$ & 0.17 & \\
\hline 6 & 626 & 3.48 & 548 & 3.04 & $6 \%$ & 0.19 & \\
\hline 7 & 617 & 3.43 & 462 & 2.57 & $6 \%$ & 0.16 & \\
\hline 8 & 648 & 3.60 & 570 & 3.17 & $6 \%$ & 0.20 & \\
\hline 9 & 642 & 3.57 & 524 & 2.91 & $6 \%$ & 0.18 & \\
\hline 10 & 631 & 3.51 & 532 & 2.96 & $6 \%$ & 0.18 & \\
\hline 11 & 645 & 3.58 & 552 & 3.07 & $6 \%$ & 0.20 & \\
\hline 12 & 633 & 3.52 & 530 & 2.94 & $6 \%$ & 0.18 & \\
\hline 13 & 647 & 3.59 & 548 & 3.04 & $6 \%$ & 0.19 & \\
\hline 14 & 630 & 3.50 & 546 & 3.03 & $6 \%$ & 0.19 & \\
\hline 15 & 647 & 3.59 & 478 & 2.66 & $6 \%$ & 0.17 & \\
\hline 16 & 642 & 3.57 & 538 & 2.99 & $6 \%$ & 0.19 & \\
\hline Total & & 56.33 & & & & 2.85 & \\
\hline
\end{tabular}

\subsection{Pembahasan}

\subsubsection{Uji Validitas}

Uji validitas dilakukan untuk mengetahui keakuratan kuisioner yang telah disebar. Uji validitas dilakukan dengan menggunakan software SPSS 22 for Windows. Hasil yang didapat pada tabel 2 . dalam uji validitas adalah nilai $r_{\text {hitung }}$ dan $r_{\text {tabel }}$ dari semua butir pertanyaan pada atribut tingkat kepentingan dan kinerja disimpulkan bahwa semua butir pertanyaan pada kuisioner yang ada adalah valid, dikarenakan nilai $r_{\text {hitung }} \geq r_{\text {tabel }}$. Hasil perhitungan nilai $r_{\text {hitung }}$ pada tabel nilai Correct Item - Total Corelation, sementara nilai $r_{\text {tabel }}$ sebesar 0,1463 .

\subsubsection{Uji Reliabilitas}

Atribut pertanyaan yang sudah valid kemudian dilakukan uji reliabilitas untuk mengukur kesuaian antara jawaban seseorang terhadap pertanyaan yang ada. Hasil yang 
didapatkan dalam uji reliabilitas adalah nilai $r_{\text {hitung }}$ dan $r_{\text {tabel }}$ dari semua butir pertanyaan pada atribut tingkat kepentingan dan kinerja semua butir pertanyaan pada kuisioner yang ada adalah reable, dikarenakan nilai $r_{\text {hitung }}$ pada atribut tingkat kepentingan sebesar 0 . 945 dan tingkat kinerja sebesar $0.864 \geq \mathrm{r}_{\text {tabel }}$. Hasil perhitungan nilai $r_{\text {hitung }}$ dengan menggunaknan software SPSS 22 for windows dapat dilihat pada tabel nilai Cronbach Alpha, sementara nilai $\mathrm{r}_{\text {tabel }}$ sebesar 0,1463 .

\subsubsection{Perhitungan Servperf dan IPA}

Penilaian kepuasan penumpang bus terhadap tingkat kepentingan dan tingkat kepuasan diolah menggunakan metode servperf untuk mendapatkan rata-rata tingkat kepentingan dan kepuasan. Nilai rata-rata kepentingan yang di dapat adalah 3.52, sedangkan untuk nilai rata-rata kinerja adalah 2.85 .

Importance performance analysis (IPA) dilakukan dengan menghitung skor total kinerja pelayanan dan tingkat kepentingan pelanggan pada penumpang bus di terminal bus jombor yang akan dipetakan ke dalam diagram kartesius. Langkah pertama dilakukan analisis tingkat kesesuaian untuk mengetahui atribut mana saja yang perlu dipertahankan dan tidak. Pemilihan atribut tersebut berdasarkan tolak ukur nilai rata-rata tingkat kesesuaian yang didapat. Hasil perhitungan rata-rata tingkat kesesuaian yang didapat adalah $81 \%$. Terdapat lima atribut yang perlu dilakukan perbaikan yaitu: ruang tunggu yang nyaman, musholla \& toilet yang nyaman, kondisi bus yang baik, keamanan di lokasi terminal bus, tempat parkir dan pengelolaan yang aman dan strategis.

Hasil pemetaan atribut ke dalam diagram kartesius yang termasuk atribut ke dalam kuadaran I adalah musholla \& toilet yang nyaman, ruang tunggu yang nyaman, kondisi bus yang baik dan keamanan di lokasi terminal bus, atribut ke dalam kuadran II adalah kejelasan jadwal keberangkatan dan kedatangan bus, karyawan cepat tanggap terhadap masalah atau keluhan penumpang, karyawan bersikap dan berkomunikasi ramah dan sopan kepada penumpang, pelayanan yang adil kepada semua pihak, kemudahan proses pembelian tiket, atribut ke dalam kuadaran III adalah tempat parkir dan pengelolaan yang aman dan strategis, penampilan karyawan yang rapih dan enak dipandang, atribut ke dalam kuadaran IV adalah loket agen yang memadai, kecepatan dan ketepatan proses pelayanan, pengangkutan dan penurunan penumpang sesuai dengan lokasi yang dituju, pintu masuk dan keluar yang mudah dijangkau.

Atribut-atribut yang termasuk ke dalam kuadran I yang berarti tingkat kepentingan tinggi akan tetapi nilai kinerja instansi terkait masih rendah, hal tersebut perlu adanya perbaikan disetiap atribut tersebut dengan cara:

1. Musholla dan Toilet di Terminal Bus Jombor Sleman.

Menambahkan alat solat serta menjaga kebersihannya, menambahkan speaker di masjid, menambahkan tempat wudhu dan melakukan renovasi agar tidak terlalu dekat dengan kamar mandi, adanya papan petunjuk arah di dekat pintu masuk yang lebih terlihat jelas sehingga penumpang mengetahui di mana lokasi musholla dan toilet di terminal. Melakukan penambahan petugas kebersihan agar lingkungan sekitar musholla dan toilet lebih rapih, bersih dan indah dilihat. Melakukan renovasi terhadapat toilet dan musholla agar letaknya tidak terlalu berdekatan dan melakukan renovasi untuk musholla agar ruangan dapat menampug jumlah jamaah yang lebih banyak lagi.

2. Ruang Tunggu.

Melakukan renovasi pada kursi tunggu dengan pembuatan ulang desain kursi tunggu yang nyaman. Menambahkan alat bantu speaker agar penumpang mendengar dan mengetahui informasi yang diberikan di terminal bus Jombor. Menambahkan dan menanam beberapa 
pohon agar lingkungan sekitar terminal terasa sejuk dan mengurangi asap polusi kendaraan yang lalu lalang. Melakukan penambahan petugas kebersihan agar lingkungan sekitar terminal lebih rapih, bersih dan indah dilihat. Relokasi ruang tunggu agar tidak terlalu dekat dengan tempat parkir bus sehingga tidak menyebabkan penumpang merasa tidak nyaman terhadap udara di sekitar lingkungan terminal dan terhindar dari polusi udara kendaraan yang lalu lalang.

3. Kondisi Bus di Terminal Bus Jombor Sleman.

Melakukan renovasi pada kursi penumpang dengan mengganti beberapa kursi penumpang yang rusak atau mendesain ulang kursi penumpang di beberapa bus yang kurang nyaman. Supir bus lebih berhati-hati dalam mengendari bus di mana perlu mentaati peraturan yang berlaku dan tidak mengendari bus secara ugal-ugalan. Emisi yang berasal dari bus yang perlu dilakukan pengawasan apa kah bus tersebut layak beroprasi atau tidaknya, sehingga tidak mengganggu kenyamanan penumpang dalam menggunakan bus.

4. Keamanan di Terminal Bus Jombor Sleman.

Menambahkan cctv di lokasi tertentu, menambahkan speaker agar penumpang mengetahui informasi yang diberikan pihak terminal dan adanya pos penjaga untuk memantau secara langsung kondisi di lapangan. Melakukan penambahan petugas keamanan agar lingkungan sekitar terminal terjaga keamanannya. Diperlukan penambahan lokasi area pengawasan agar dapat membentuk pos pengawas keamanan.

Atribut-atribut yang termasuk ke dalam kuadran II yang berarti tingkat kepentingan tinggi dan sudah sesuai dengan kepuasan pelanggan, sehingga perlu dilakukan pertahanan dalam setiap atribut agar kualitas pelayanan tidak menurun dengan cara:
1. Kejelasan jadwal keberangkatan dan kedatangan bus.

Pihak terminal tepat dan akurat dalam memberikan informasi jadwal keberangkatan dan kedatangan bus agar penumpang tidak merasa lama menunggu atau tidak ketinggalan bus yang akan digunakan.

2. Karyawan cepat tanggap terhadap masalah atau keluhan penumpang.

Karyawan selalu siap sedia dan tidak merasa sibuk dalam menangani keluhan penumpang yang diajukan.

3. Karyawan bersikap dan berkomunikasi ramah dan sopan kepada penumpang.

Karyawan selalu menjaga komunikasi dengan baik dan sopan agar penumpang bus merasa nyaman dan puas atas pelayanan yang diberikan pihak terminal.

4. Pelayanan yang adil kepada semua pihak.

Pihak terminal tidak membeda-bedakan status dalam proses pelayanan, serta mengutamakan system antrian sehingga pelayanan yang diberikan berjalan dengan terstruktur.

5. Kemudahan proses pembelian tiket.

Pihak terminal menyediakan beberapa tempat untuk membeli tiket sehingga penumpang tidak perlu jauh-jauh pergi membeli tiket ke agen bus. Cara tersebut dapat dilakukan dengan mengadakan loket agen penjualan tiket atau melakukan pemesanan tiket melalu alat komunikasi seperti handphone.

\subsubsection{Perhitungan Customer Satisfaction Index}

Customer Satisfacton Index digunakan untuk mengetahui tingkat kepuasan pengunjung secara menyeluruh dengan melihat tingkat kepentingan dari atributatribut produk/jasa. Hasil perhitungan CSI dapat disimpulkan bahwa indeks pelayanan publik di terminal bus Jombor sebesar 71\%, berada pada kategori "Poor" dan masih perlu dilakukan perbaikan. 


\section{KESIMPULAN}

Berdasarkan penelitian yang telah dilakukan dapat disimpulkan bahwa kualitas pelayanan publik di terminal bus Jombor Sleman menunjukkan sebagian besar responden merasa kurang puas terhadap pelayanan jasa yang telah diberikan. Hal tersebut berdasarkan perhitungan customer satisfaction index dengan hasil perhitungan $71 \%$ yang termasuk ke dalam kategori "poor". Atribut-atribut yang perlu dilakukan perbaikan dalam kategori kuadaran I adalah musholla \& toilet yang nyaman, ruang tunggu yang nyaman, kondisi bus yang baik dan keamanan di lokasi terminal bus.

Usulan perbaikan yang dapat diberikan untuk meminimalisir permasalahan yang terjadi adalah pemeriksaan terhadap kondisi bus dan pemberian izin layak atau tidaknya beroprasi, renovasi ruang tunggu penumpang, renovasi musholla dan toilet, pembuatan pos penjaga, serta menambahkan beberapa material yang dibutuhkan seperti alat sholat, speaker, cctv, papan petunjuk arah, penanaman beberapa tumbuhan agar membuat lingkungan sekitar terminal terasa sejuk dan dapat mengurangi polusi udara.

\section{DAFTAR PUSTAKA}

Aritonang, R. L. Kepuasan Pelanggan. Jakarta: Gramedia. 2005.

Cronin, J. Joseph, Jr. Steven A. \& Taylor. SERVPERF Versus SERVQUAL:Reconciling Performance Based and Perception Minus Expections Measurement of Service Quality. Journal Of Marketing. 58:125131. 1994.

Cronin, J. Joseph, Jr., Steven A. \& Taylor. Measuring Service Quality A Reexamination and Extension. Journal of Marketing. 56: 55-68. 1992.

Edward, K. Pengantar Teknik dan Perencanaan Transportasi. Jakarta: Erlangga. 1998.
Efranto, R. Y. Moses, L. S. \& Mokh, S. Evaluasi Model Peningkatan Kualitas Pelayanan Dengan Pendekatan Servperf Six Sigma. 2008.

Hair, et al. Multivariate Data Analysis. McGrawhill. New York. 2006.

Hudaya \& Medina A. R. Peningkatan Kualitas Pelayanan Di Unit Farmasi Rawat Jalan Berdasarkan Tingkat Kepuasan Pelanggan Menggunakan Pendekatan Lean Servperf. Journal of Industrial Research. 1: 27-36. 2011.

Kotler. Manajemen Pemasaran di Indonesia: Analisis, Perencanaan, Implementasi dan Pengendalian. Jakarta: Salemba Empat. 2001.

Kotler. Manajemen Pemasaran di Indonesia: Analisis, Perencanaan, Implementasi dan Pengendalian. Salemba Empat. Jakarta. 2002.

Lupiyoadi, R. \& Hamdani, A. Manajemen Pemasaran Jasa. Salemba Empat. Jakarta. 2001.

nn. Pengertian Definisi Kualitas Menurut Para Ahli. (online): http://definisipengertian. com/2012/ pengertian-definisi-kualitas-menurutpara-ahli/ (Online : 27 Juli 2015) 2012.

Novel, H \& Humala, L. N. Penilaian Tingkat Kepuasan Pasien Terhadap Pelayanan Jasa Puskesmas Medan Johor Dengan Metode Servperf (Service Performance) Dan Customer Satisfaction Index. Jurnal Teknik Industri FT USU. 2: 18-22. 2013.

Parasuraman, A. Valarie, A Z. Leonard, L \& Berry. A Conceptual Model of Service Quality and its Implications for Future Research. Journal of Marketing. 49: 41-50. 1985. 
Prajogo, et al. Examining Competitive Priorities and Competitive Advantages in Service Organization Using IPA Matrix. Managing Service Quality. 5: 465-483. 2011.

Rizal, N. Ambar, H. Hari, A. Usulan Peningkatan Kualitas Pelayanan Jasa pada Bengkel " $X$ " Berdasarkan Hasil Matrix Importance-Performance Analysis. Jurnal Online Institut Teknologi Nasional. 3. 2014.

Setyaningsih, I. Analisis Kualitas Pelayanan Rumah Sakit Terhadap Pasien Menggunakan Pendekatan Lean Servperf (Lean Service Dan Service Performance). 2: 117-242. 2013.

Siregar, S. F. Analisis Tingkat Kualitas Pelayanan dengan Metode Index Potential Gain Customer Value (Pgcv) Di Pt Bank Muamalat Indonesia Cabang Medan. Jurnal Sistem Teknik Industri. 4. 2006.

Sukania, I. W. Kajian Ergonomi Terminal Bus Di Jakarta. Jurnal Ilmiah Teknik Industri. 1: 33-40. 2013.

www. leadershipfactor. com. Customer Satisfaction Index.

Yamit, Z. Manajemen Kualitas Produk dan Jasa. Sleman: Ekonosia. 2002. 